\title{
The Effect of Waiting for Surgery on Patients with Adolescent Idiopathic Scoliosis
}

\author{
Fallatah $\mathbf{S}^{1 *}$, Sait $\mathbf{M}^{2}$ and Almutairi $\mathbf{F}^{2}$ \\ ${ }^{1}$ Faculty of Medicine, Umm Al-Qura University, Saudi Arabia \\ ${ }^{2}$ Faculty of Medicine, King Abdulaziz University, Saudi Arabia
}

\begin{abstract}
The waiting time for surgical procedures is becoming longer in most specialties. This may have adverse effect on patients with Adolescent Idiopathic Scoliosis (AIS) with additional procedures being required or more complex surgery being performed. This retrospective study was performed in the period between December 2007- January 2010 looking on the surgical waiting time on patients with AIS and its effect on curve progression and the type of surgery performed and the final outcome.
\end{abstract}

215 patients met the inclusion criteria and have complete medical records to be included in the study. Mean age was 13.6 years, 184 patients ( $86 \%$ ) were females, 172 were treat in public hospitals and 43 in a private hospital, mean cobb angle of the main curve was $71^{\circ}$. During the study period, 55 patients underwent surgery for scoliosis correction, with a statistical difference in the waiting time between public and private hospitals ( 36 and 9 weeks respectively), average curve progression was $24^{\circ}$ during the waiting period with additional fusion levels being required in 15 cases. Patients with underlying intra spinal pathology and young patients showed the most significant curve progression.

Our study support the previous report of the optimal waiting time for surgical correction of scoliosis being less than 6 months and it suggest those younger patients and those with intra spinal pathology and the ones at higher risk for progression.

Keywords: Idiopathic scoliosis; Surgical waiting; Curve progression

\section{Introduction}

The waiting list for an elective surgical procedure could be long in public health care system. This is even longer for cases of scoliosis correction and other spine procedures [1] Idiopathic scoliosis affects $1-3 \%$ of young population but surgical treatment is only needed in less than $10 \%$ of the cases [2-5]. It has been reported that the odds of adverse events for scoliosis surgery triple after 6 months of waiting compared to one day of waiting. Additional surgery such as anterior release, longer fusion, or increased risk of complications might be associated with this prolonged waiting time for surgery due to curve progression in addition to the anxiety experienced by the patients and parents during this waiting period. Ahn et al. Suggested that 3 months could be the maximum acceptable waiting time for surgery in scoliosis to eliminate the need for additional surgery by reducing curve progression [6,7]. This potential increased risk of complication with increased waiting time has been well documented in other subspecialties [8-10]. The purpose of this study is to evaluate the surgical waiting time on patients with AIS in the Kingdom of Saudi Arabia from the time when a decision was made to proceed to surgical treatment option to the time of actual surgery performed or to the time of last follow up while still on the waiting list to try to determine the effect of this waiting time on curve progression, type of procedure performed, and compare that with the current recommendations.

\section{Material and Methods}

The medical records of patients who underwent surgery or are on the waiting list for AIS in the period between Dec 2007-Jan 2010 in three hospitals (two public and one private) were retrospectively reviewed. Data abstracted included patients demographics; time from the decision to proceed to surgery to the actual date of surgery or the most recent follow up is recorded. The indications for surgery were trunk imbalance in the presence of a thoracic curve $\geq 50^{\circ}$ and/or a lumbar curve $\geq 45^{\circ}$ in the age group between 11-18. Their pre and post-operative plain radiographs were reviewed for curve type and magnitude according to Lenke classification [2], fusion level, All patients included in this study filled the Scoliosis Research Society-30 questionnaire pre operatively and after surgery for those who underwent the operation. Patients with neuromuscular, congenital, syndromic, juvenile or infantile idiopathic scoliosis were excluded from the study, as well as patients older than 18 or younger than 10 years. Other outcomes that we looked at included: curve progression (defined as more than 10 degrees increase in cobb angles between the $\mathrm{x}$-rays taken when surgery is scheduled and the one just before surgery), curve correction percentage (the percentage of improvement in cobb angles between the immediate post-operative $\mathrm{x}$-rays and the preoperative $\mathrm{x}$-rays), and postoperative complications. All patients presented with curves qualify for surgical treatment was included in this study.

\section{Results}

Two hundred and eighty-five patients were identified, but only 215 met our inclusion criteria or have complete medical records to be included in the study. 184 were females (86\%) and 31 (14\%) were males. 172 patients were treated in the public hospitals and 43 were treated in a private hospital. The mean age at presentation was 13.6 year, average cobb angle of the main curve was $71^{\circ}$ (range 45-120) at the time when surgery was decided, which increased by an average of $24^{\circ}$ (range 8-30) while awaiting surgery with a flexibility of about $40 \%$ in the major curve. The most common curve types were Lenke type 1 (48\%) and 3 (41.4\%). The average waiting time to surgery was statistically different between the public and private hospitals, 36 and 9 weeks respectively $(\mathrm{P}<0.05)$. Nine patients had associated intra-spinal pathology (Arnold-

*Corresponding author: Fallatah S, Faculty of Medicine, Umm Al-Qura University, Saudi Arabia, Tel: 66555708176; E-mail: salahmf@mac.com

Received March 13, 2015; Accepted March 30, 2015; Published April 02, 2015

Citation: Fallatah S, Sait M, Almutairi F (2015) The Effect of Waiting for Surgery on Patients with Adolescent Idiopathic Scoliosis. J Spine 4: 224 doi:10.4172/21657939.1000224

Copyright: ( 2015 Fallatah S, et al. This is an open-access article distributed under the terms of the Creative Commons Attribution License, which permits unrestricted use, distribution, and reproduction in any medium, provided the original author and source are credited. 
Chairi malformation-I [4], Syrigomylia [3], Diastatomylia [2], they showed a clinical but not statistical significant progression of their curves compared to the rest of the patients while they were awaiting their neurosurgical or deformity correction procedures $(\mathrm{P}>0.05)$. A 13 year old boy with Arlond Chairi malformation-I and syringomylia had a $50^{\circ}$ thoracic curve which progressed to $80^{\circ}$ over the period of 8 months while awaiting the neurosurgical procedures (Figure 1). During the study period, 55 patients out of the 215 underwent surgical correction of their scoliosis and this group of surgically treated patients was further analyzed for any change in the number of fusion levels, type of procedure performed compared to the initial plan. All surgeries were performed by one surgeon using a standardized technique. The average surgical time excluding anesthesia was 390 minutes and the estimated blood loss was $750 \mathrm{cc}$. Anterior surgery only or combined with posterior surgery was performed in 10 cases only. Only one patient was placed in halo-femoral traction for 2 weeks between the anterior release and posterior scoliosis correction. Twenty-two patients (40\%) needed additional fusion levels at the time of surgery compared to the initially planned fusion levels when the $\mathrm{x}$-rays at the time of surgical decision were compared to the immediate preoperative $\mathrm{x}$-rays and post-operative $\mathrm{x}$-rays. The waiting time for surgery did not lead to additional surgical procedures except for more fusion levels proximally and distally (i.e. Anterior release, or combined anterior and posterior procedures were not added except for those already scheduled for such interventions). Five patients (9\%), all underwent selective fusion, developed progression of their curve proximal or distal to the fusion levels for which further surgical procedures to extend their fusion were needed, one patient (1.8\%) developed post-operative lower extremities weakness post operatively due to mis placed screw and he made full recovery after urgent return to the operating room for removal of the mis placed screw and less correction of the deformity. No cases of infection reported in this series and 2 patient developed corneal abrasion which improved with conservative treatment, for a total of 8 complications (14\%) in the surgically treated group. The surgically treated group showed significant improvement in all domains of the SRS-30 (function, pain, cosmetics, mental health, and overall satisfaction) when compared to the group awaiting surgery $(\mathrm{P}<0.05)$, and were satisfied with their surgical results.

\section{Discussion}

The need to shorten surgical waiting time and trying to identify an acceptable period of waiting time has been investigated in the past in various subspecialties and longer waiting time to surgery was shown to be associated with increased risk of adverse events in most cases [8-10]. Hurlbert et al. Clearly showed that patients needing spine surgery in the private hospitals have access to the operating room 4 times faster than patients in the public hospitals [1], this gap of difference might be even bigger in cases of AIS as we showed in this study. It is well established that surgical treatment of scoliosis results in significant improvement in patients quality of life and yield excellent results [11-16].

Delaying surgery in patients with scoliosis who qualified for surgical treatment is associated with increased operative time, longer fusion levels, need for combined procedures, and potential for complications $[6,7,17]$. Our study concurs with previous reports that waiting time of more than 6 months is associated with significant curve progression. Most of the patients in this study already presented late for their surgical treatment with large curves that need long fusions from the start, thus we were unable to show an increase in the fusion levels due to the long wait. The group of patients that underwent surgical treatment had segmental or hybrid fixation and wide posterior release, a reason why we were unable to show an increase in the need
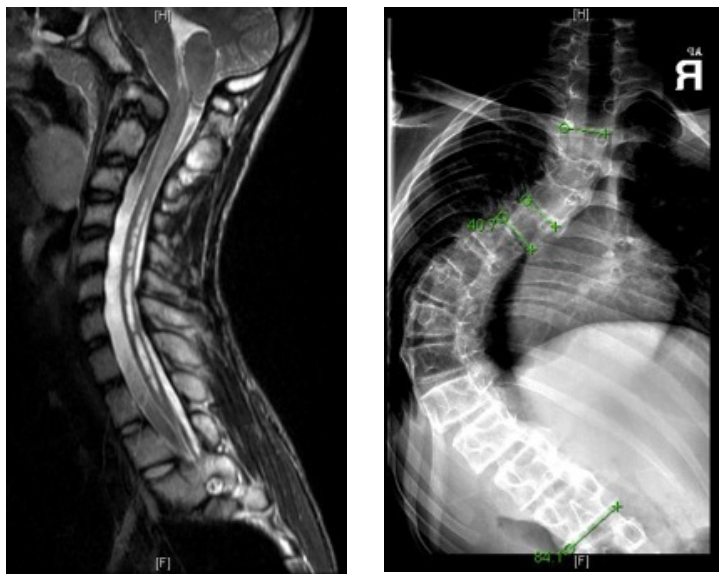

Figure 1: 13 year old boy with arlond-chairi malformation (A) Type I and 85 degrees Lt thoracic $(B)$ curve.

for anterior release with this long waiting time to surgical treatment. The relatively high percentage of complications in the surgically treated group is mostly due to the need for extension of fusion in 5 cases out of $55(9 \%)$, only one patient developed new post-operative neurological deficit with complete recovery on follow up [17-20]. The unacceptably long waiting time for surgery in our patient's population could be related to limited number of surgeons performing such procedures, and the unavailability of intra operative neuro monitoring in most hospitals. Some of the limitations of our study in addition to being a retrospective analysis, we were unable to analyse the menarchal status, skeletal age and peak height velocity of our cohort, all of which are known risk factors for curve progression. We found that patients with associated intra spinal pathology and younger patients are the ones to show the most rapid progression of their curves while awaiting surgery. Therefore those patients should be prioritized when scheduled for surgery.

\section{References}

1. Hurlbert RJ, Mobbs R, Teo C (2008) Access to spine care: a tale of two cities Can J Neurol Sci. 35: 308-313.

2. Weinstein SL, Zavala DC, Ponseti IV (1981) Idiopathic scoliosis: long-term follow-up and prognosis in untreated pateints. J bone joint Surg Am 63: 702712.

3. Weinstein SL, Ponseti IV (1983) Curve progression in idiopathic scoliosis. J Bone Joint Surg Am 65: 447-455.

4. Smymis T, Antoniou D, Valavanis J, Zachariou C (1987) Idiopathic scoliosis: characteristics and epidemiology. Orthopedics 10: 921-926.

5. Escalada F, Marco E, Durte E, Muniesa JM, Belmonte R, et al. (2005) Growth and curve stablization in girls with adolescent idiopathic scoliosis. Spine 30 411-417.

6. Ahn H, Kreder H, Mohomed N, Beaton D, Wright JG (2011) Empirically derived maximal acceptable wait time for surgery to treat adolescent idiopathic scoliosis. CMAJ 183: 565-570.

7. Clark S (2008) Waiting times for scoliosis surgery. Lancet $37: 10-11$

8. Zamakhshary M, To T, Guan J, Langer JC (2008) Risk of incarceration of inguinal hernia among infants and young children awaiting elective surgery. CMAJ 179: 1001-1005

9. Cesena FH, Favarato D, César LA, de Oliveira SA, da Luz PL (2006) Ontario score and cardiac risk during waiting for elective coronary bypass grafting. Int J Cardiol 110: 167-174.

10. Chan FW, Fan AH, Wong FY, Lam PT, Yeoh EK, et al. (2009) Waiting time for cataract surgery and its influence on patient attitudes. Invest Ophthalmol Vis Sci 50: 3636-3642. 
Citation: Fallatah S, Sait M, Almutairi F (2015) The Effect of Waiting for Surgery on Patients with Adolescent Idiopathic Scoliosis. J Spine 4: 224. doi:10.4172/21657939.1000224

11. Lenke L (2005) Lenke Classification System of Adolescent Idiopathic Scoliosis: Treatment Recommendations. AAOS instructional Course Lectures, Volume 54.

12. Kim YJ, Lenke LG, Kim J, Bridwell KH, Cho SK, et al. (2006) Comparative analysis of pedicle screw versus hybrid instrumentation in posterior spinal fusion of adolescent idiopathic scoliosis. Spine 31: 291-298.

13. Carreon LY, Puno RM, Lenke LG, Richards BS, Sucato DJ, et al. (2007) Nonneurologic complications following surgery for adolescent idiopathic scoliosis. J Bone Joint Surg Am 89: 2427-2432.

14. Zhang, J, He D, Gao J, Yu X, Sun H, et al. (2011) Changes in life satisfaction and self-esteem in patients with adolescent idiopathic scoliosis with and without surgical intervention. Spine 36: 741-745.

15. Roach JW, Mehlman CT, Sanders JO (2011) "Does the outcome of adolescent idiopathic scoliosis surgery justify the rising cost of the procedures?" J Pediatr Orthop 31: 77-80.
16. Bago J, Perez-Grueso FJ, Pellise F, Les E (2012) How do idiopathic scoliosis patients who improve after surgery differ from those who do not exceed a minimum detectable change? Eur Spine J 21: 50 -56.

17. Fischer CR, Kim Y (2011) Selective fusion for adolescent idiopathic scoliosis: a review of current operative strategy. Eur Spine J 20: 1048-1057.

18. Suk SI, Kim JH, Kim SS, Lim DJ (2012) Pedicle screw instrumentation in adolescent idiopathic scoliosis (AIS). Eur Spine J 21: 13-22

19. Gang Li, Guohua Lv, Passias P, Kozanek M, Metkar US, et al. (2010) Complications associated with thoracic pedicle screws in spinal deformity. Eur Spine J 19: 1576-584.

20. Hamilton DK, Smith JS, Sansur CA, Glassman SD, Ames CP, et al. (2011) Rates of new neurological deficit associated with spine surgery based on 108,419 procedures: a report of the scoliosis research society morbidity and mortality committee. Spine 36: 1218-1228. 